\title{
Selective Phosphorylation Inhibitor of Delta Protein Kinase C- Pyruvate Dehydrogenase Kinase Protein-Protein Interactions: Application for Myocardial Injury in Vivo
}

Nir Qvit ${ }^{\dagger}$, Marie-Hélène Disatnik ${ }^{\dagger}$, Eiketsu Sho* and Daria Mochly-Rosen ${ }^{\dagger, *}$

'Department of Chemical and Systems Biology, Stanford University, School of Medicine, Stanford CA 94305-5174 USA

Nanjing, Jiangsu, 210000, P. R. China.

Supplementary information 


\section{Experimental Methods}

Peptide synthesis. All commercially available solvents and reagents were used without further purification. Dichloromethane (DCM), N-methyl-2-pyrrolidone (NMP), triisopropylsilane (TIS), N,Ndiisopropylethylamine (DIEA), O-benzotriazole-N,N,N',N'-tetramethyl-uronium-hexafluoro-phosphate (HBTU), 1-hydroxybenzotriazole (HOBt) and trifluoroacetic acid (TFA) were purchased from SigmaAldrich (MO, USA); dimethylformamide (DMF) was purchased from Alfa Aesar (MA, USA); piperidine was purchased from Anaspec (CA, USA); rink amide AM resin was purchased from CBL Biopharma LLC (substitution $0.49 \mathrm{mmol} / \mathrm{g}$, CO, USA); Fmoc-protected amino acids were purchased from Advanced ChemTech and GL Biochem (KY, USA and Shanghai, China). Side chains of the amino acids used in the synthesis were protected as follows: tert-Butyloxycarbonyl (BOC) (Lys/Trp), tert-butyl (tBu) (Ser/Thr/Tyr), t-butyl ester (OtBu) (Asp/Glu), 2,2,4,6,7-Pentamethyldihydrobenzofuran-5-sulfonyl (Pbf) (Arg), 4methyltrityl (Mtt) (Lys) and triphenylmethy (Trt) (Asn/Cys/Gln/His).

Peptides were chemically synthesized using Liberty Microwave Peptide Synthesizer (CEM Corporation, Matthews, NC, USA) on solid support with an additional module of Discover (CEM Corporation, Matthews, NC, USA) equipped with fiber-optic temperature probe for controlling the microwave power delivery following the fluorenylmethoxycarbonyl (Fmoc)/tert-Butyl (tBu) method in a $30 \mathrm{ml}$ teflon reaction vessel. Each deprotection and coupling reaction was performed with microwave energy and nitrogen bubbling.

Fmoc deprotection was performed in two steps: $30 \mathrm{sec}$ and $180 \mathrm{sec}$, both at $45 \mathrm{~W}, 75^{\circ} \mathrm{C}$ using piperidine $(20 \%)$ in DMF with HOBt $(0.1 \mathrm{M})$ solution. Coupling reactions were performed by repetition of the following cycle conditions: $300 \mathrm{sec}, 25 \mathrm{~W}, 75^{\circ} \mathrm{C}$, with $\mathrm{HBTU}(0.11 \mathrm{M})$ in DMF, amino acids (0.12 M) in DMF and DIEA (0.25 M) in NMP solution. The coupling and Fmoc deprotection steps were monitored using Kaiser (ninhydrin) Test ${ }^{1}$ and small cleavage. Anhydride coupling was carried out as follows: $300 \mathrm{sec}$, $25 \mathrm{~W}, 75^{\circ} \mathrm{C}$, using 10:10:1 anhydride/Di-isopropylethylamine (DIEA)/4-dimethylaminopyridine (DMAP) in NMP. Mtt deprotection was carried out using 1:5:94 TFA/TIS/DCM. Cyclization was performed in dibromomethane (DBM) (300 sec, $25 \mathrm{~W}, 75{ }^{\circ} \mathrm{C}$, using 5:10 benzotriazole-1-yl-oxy-tris-pyrrolidinophosphonium hexafluorophosphate (PyBOP)/DIEA). Peptide cleavage from the resin and deprotection of the amino acid side chains were carried out with TFA $/ \mathrm{TIS} / \mathrm{H}_{2} \mathrm{O} /$ phenol solution $(90: 2.5: 2.5: 5 \mathrm{v} / \mathrm{v} / \mathrm{v} / \mathrm{w})$ for three hours at room temperature without microwave energy. The crude products were precipitated with diethyl ether, collected by centrifugation, dissolved in $\mathrm{H}_{2} \mathrm{O} / \mathrm{CH}_{3} \mathrm{CN}$ and lyophilized.

Products were analyzed by analytical reverse-phase high-pressure liquid chromatography (RP-HPLC) (Shimadzu LC-20 equipped with: CBM-20A system controller, SPD-20A detector, CTO-20A column oven, $2 \times$ LC-20AD solvent delivery unit, SIL-20AC autosampler, DGU-20A5 degasser from Shimadzu, MD, USA) using an ultro $1205 \mu \mathrm{m}$ C18Q (4.6 mm ID $\times 150 \mathrm{~mm}$ ) column (Peeke Scientific, CA, USA) at 1 $\mathrm{mL} / \mathrm{min}$. The solvent systems used were $\mathrm{A}\left(\mathrm{H}_{2} \mathrm{O}\right.$ with $0.1 \%$ TFA $)$ and $\mathrm{B}\left(\mathrm{CH}_{3} \mathrm{CN}\right.$ with $\left.0.1 \% \mathrm{TFA}\right)$. A linear gradient of $5-50 \% \mathrm{~B}$ in $15 \mathrm{~min}$ was applied and the detection was at $215 \mathrm{~nm}$.

The synthesis products were purified by preparative RP-HPLC (Shimadzu LC-20 equipped with: CBM20A system controller, SPD-20A detector, CTO-20A column oven, $2 \times$ LC-6AD solvent delivery unit and FRC-10A fraction collector from Shimadzu, MD, USA), using an XBridge Prep OBD C18 $5 \mu \mathrm{m}(19 \mathrm{~mm}$ $\times 150 \mathrm{~mm}$ ) column (Waters, MA, USA) at $10 \mathrm{~mL} / \mathrm{min}$. The solvent systems used were $\mathrm{A}\left(\mathrm{H}_{2} \mathrm{O}\right.$ with $0.1 \%$ TFA) and $\mathrm{B}\left(\mathrm{CH}_{3} \mathrm{CN}\right.$ with $0.1 \%$ TFA). For separation, a linear gradient of 5-50\% B in 45 min was applied and the detection was at $215 \mathrm{~nm}$. 
Cage Observation Test. Male and female mice were purchased from the Jackson Laboratory (BALB/c). Mice were maintained with a 12-hour light/12-hour dark cycle (on at 6:00 am, off at 6:00 pm). 4 female and 3 male BALB/c mice received $\psi \mathrm{PDK} 1$ peptide, and 4 female and 4 male BALB/c mice received TAT control peptide. The mice were implanted with a subcutaneous 42-day osmotic pump $(\# 2002,0.5 \mu 1 / \mathrm{h}$, Alzet, Ca, USA) containing either $\psi$ PDK1 or TAT peptide, which delivered peptides to the mice at a rate of $2 \mathrm{mg} / \mathrm{kg} /$ day. 6 weeks after implantation, the mice were tested to assess general activity levels. Mice were habituated to a well lit testing room at least 1 hour prior to start of test. The mice were placed in a clean cage with clean bedding for 10 minutes and were recorded using a Sony HandyCam full HD camcorder, model number: HDR-CX220/R. Mice were returned to home cages at the end of testing. Using automated tracking with the Ethovision XT software (Noldus Information Technology) the distance moved and average velocity were acquired over the 10 minute trial. An experimenter blind to the treatment groups assessed other parameters such as digging, grooming, rearing, and climbing. 


\section{Supplementary Scheme 1. General scheme for peptide synthesis}
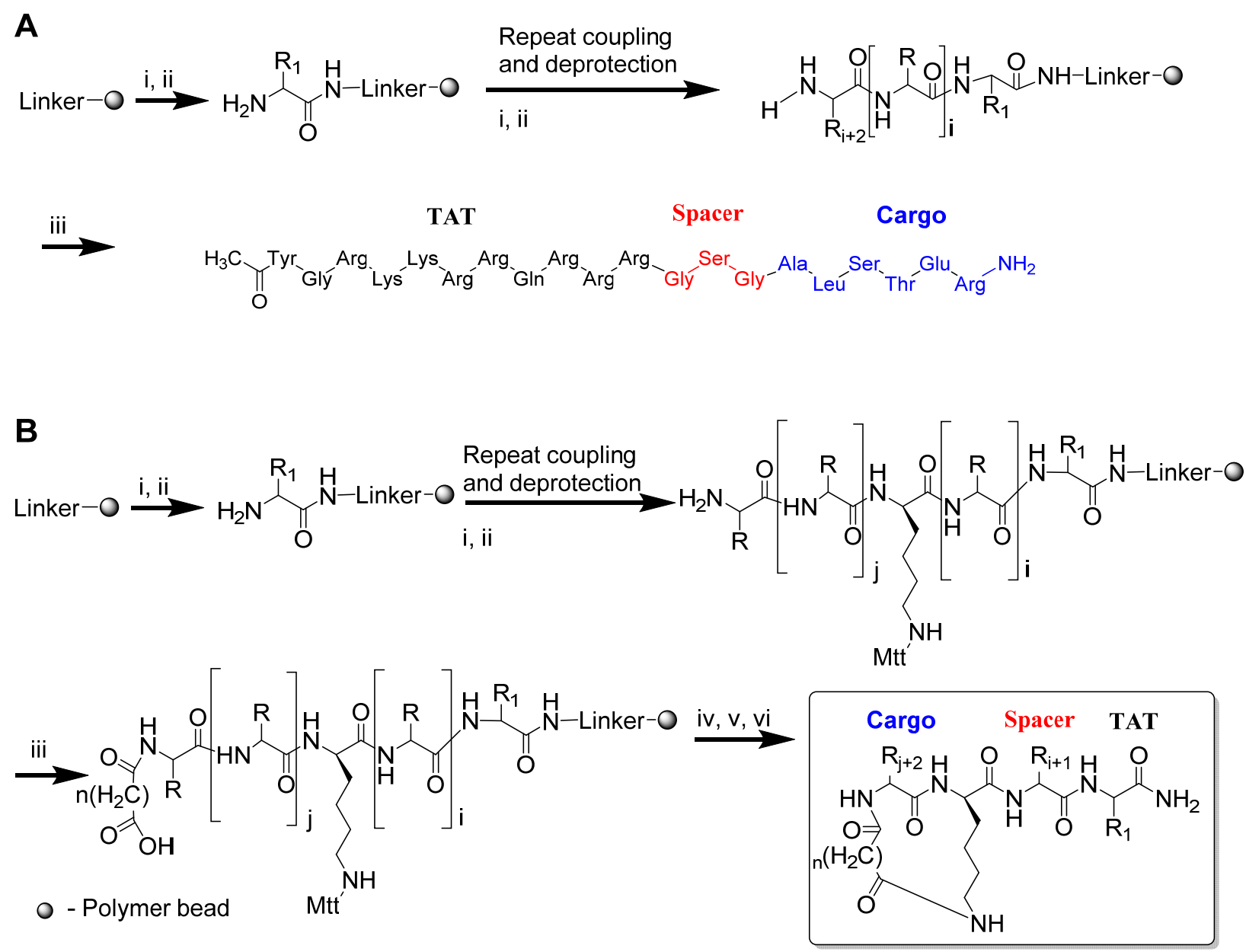

(A) Synthesis of linear peptides, reagents and conditions: (i) Amino acid coupling: $300 \mathrm{sec}, 25 \mathrm{~W}$, $75^{\circ} \mathrm{C}$, using 1.1:1:2.2 amino acid/activator/activator base. (ii) Fmoc deprotection: 30 sec and 180 sec both at $45 \mathrm{~W}, 75{ }^{\circ} \mathrm{C}$, using $20 \%$ piperidine in DMF $+0.1 \mathrm{M}$ HOBt. (iii) Cleavage and deprotection: 3 h, 0 W, rt, using 90:2.5:2.5:5 TFA/TIS/ $\mathrm{H}_{2} \mathrm{O} /$ phenol. (B) Synthesis of cyclic peptides, reagents and conditions: (i) Amino acid coupling: $300 \mathrm{sec}, 25 \mathrm{~W}, 75^{\circ} \mathrm{C}$, using 1.1:1:2.2 amino acid/activator/activator base. (ii) Fmoc deprotection: $30 \mathrm{sec}$ and $180 \mathrm{sec}$ both at $45 \mathrm{~W}, 75$ ${ }^{\circ} \mathrm{C}$, using $20 \%$ piperidine in DMF $+0.1 \mathrm{M} \mathrm{HOBt}$. (iii) Anhydride coupling: $300 \mathrm{sec}, 25 \mathrm{~W}, 75^{\circ} \mathrm{C}$, using 10:10:1 anhydride/DIEA/DMAP in NMP. (iv) Mtt deprotection: $3 \times(5 \mathrm{~min}, 0 \mathrm{~W}$, rt $)$ using 
1:5:94 TFA/TIS/DCM. (v) Cyclization: $300 \mathrm{sec}, 25 \mathrm{~W}, 75^{\circ} \mathrm{C}$, using 5:10 PyBOP/DIEA in DBM.

(vi) Cleavage and deprotection: $3 \mathrm{~h}, 0 \mathrm{~W}$, rt, using 90:2.5:2.5:5 TFA/TIS/ $\mathrm{H}_{2} \mathrm{O} /$ phenol. 
Supplementary Figure 1.

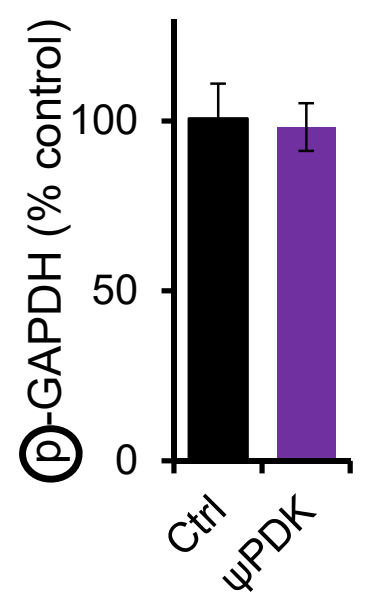

Supplementary Figure 1. $\psi$ PDK peptide does not affect the phosphorylation of other $\delta$ PKC substrates, such as GAPDH in vitro. (A) The phosphorylation of GAPDH substrate was evaluated in vitro with $\psi \mathrm{PDK}(1 \mu \mathrm{M})$ relative to control peptide. Data are representative of three independent experiments and presented as mean \pm SEM. 


\section{Supplementary Figure 2.}

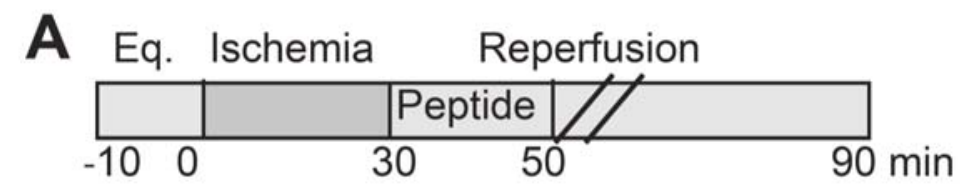

B

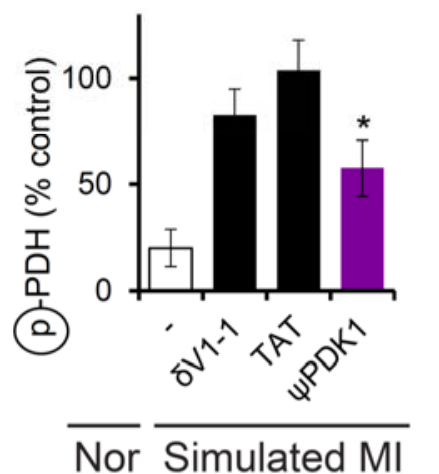

Myocardial infarction (whole heart I/R studies), ex vivo

\section{Supplementary Figure 2. PDD peptide selectivity for PDK phosphorylation; measurement}

in whole heart subjected to simulated myocardial infarction ex vivo. (A) Protocol of simulated myocardial infarction model (ischemia and reperfusion; I/R) using isolated hearts. Bars indicate the length (in minutes) of each treatment (eq = equilibration). Rats were subjected to $30 \mathrm{~min}$ ischemia and 60 min reperfusion without or with peptide treatment. (B) Total rat heart extracts following ex vivo ischemia and reperfusion were analyzed by 2-D IEF gel and phosphorylation of the PDK substrate, PDH were evaluated by a shift towards lower $\mathrm{pH}$. Data are representative of three independent experiments and presented as mean \pm SEM. 


\section{Supplementary Figure 3.}

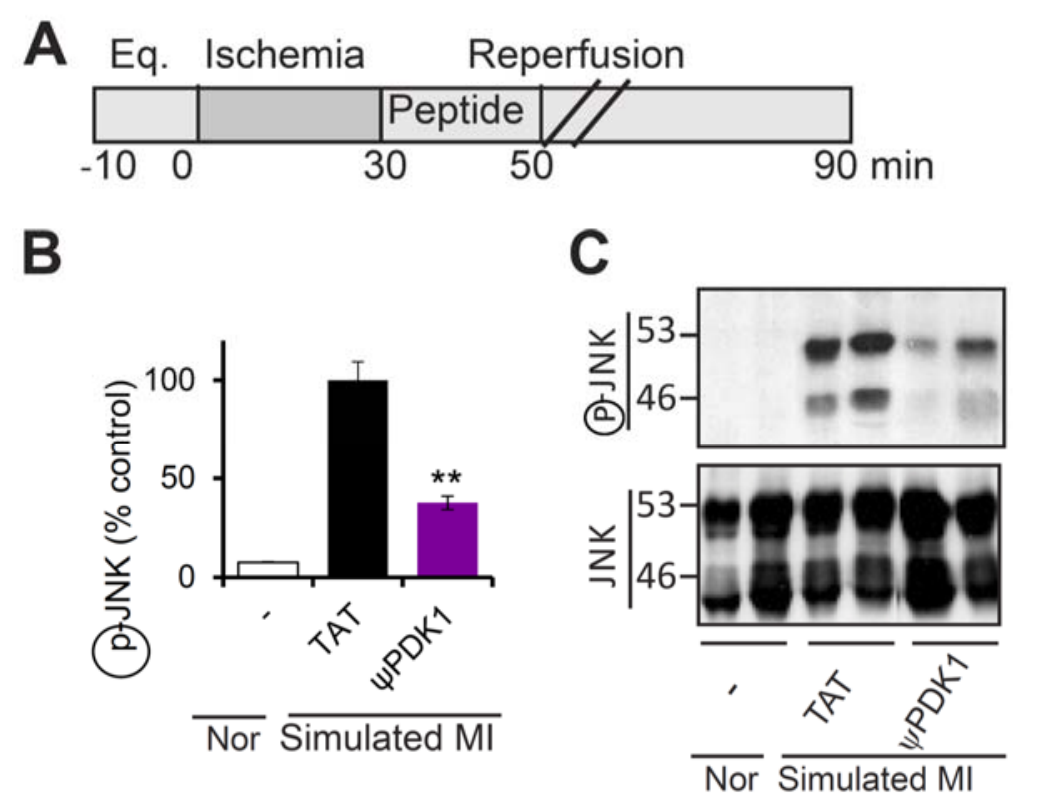

Myocardial infarction (whole heart I/R studies), ex vivo

Supplementary Figure 3. Cardiac protection against ischemia and reperfusion injury. (A)

Protocol of myocardial infarction model using isolated hearts subjected to ischemia and reperfusion. Bars indicate the length (in minutes) of each treatment (eq=equilibration). Rats were subjected to $30 \mathrm{~min}$ ischemia and $60 \mathrm{~min}$ reperfusion without or with peptide treatment. (B) Infarct size following simulated myocardial infarction was determined by analyses of the levels of phosphorylated JNK (expressed relative to total JNK; n=6) $(\mathbf{B}, \mathbf{C})$. Data are presented as mean \pm SEM. ${ }^{* *} \mathrm{p}<0.01$ compared to TAT control. 


\section{Supplementary Chart 1.}

4 PDK1:

TAT-Sp- $\psi$ PDK

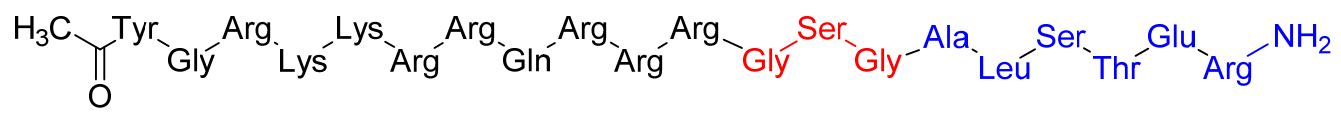

४PDK5:

TAT-Sp-AASTER

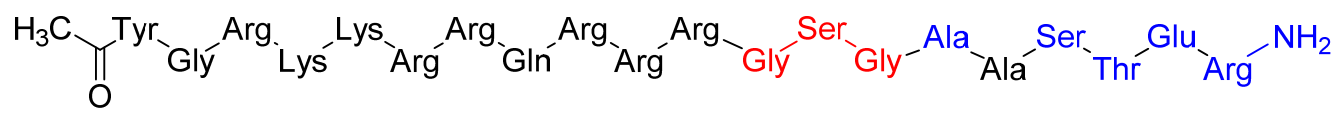

4 PDK6:

TAT-Sp-ALATER

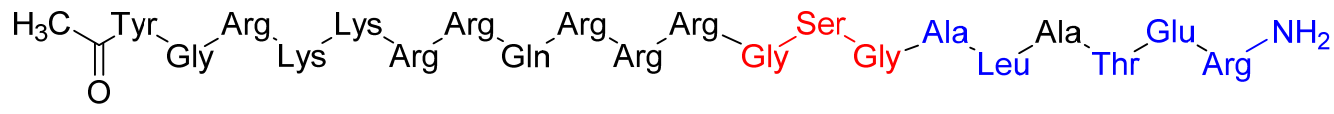

४PDK7:

TAT-Sp-ALSAER

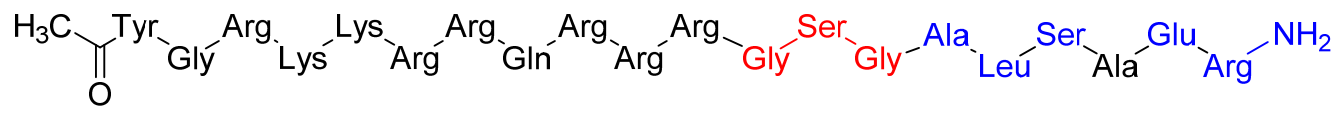

४PDK8:

TAT-Sp-ALSTAR

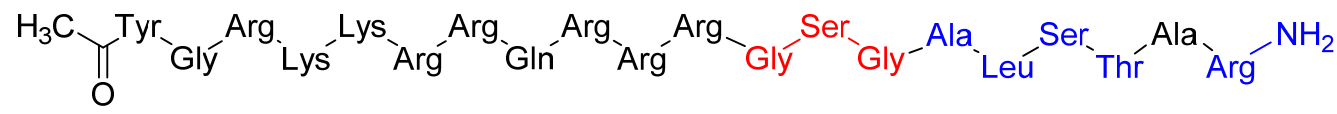

४PDK9:

TAT-Sp-ALSTEA

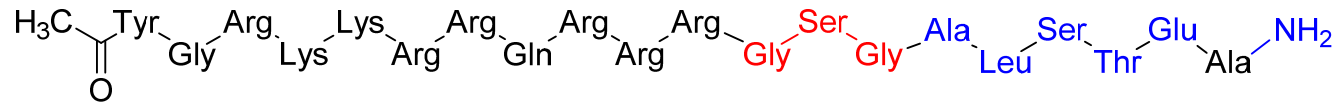

Supplementary Chart 1. Ala scan analgous. The peptides are comprised of: TAT47-57, a short positively charged peptide that is used as a carrier for the delivery of the peptides into the cell (black); a spacer (Sp), composed of three amino acids used as spacers between TAT and the cargo (red); and the cargo (blue). 
Supplementary Figure 4.

(A)

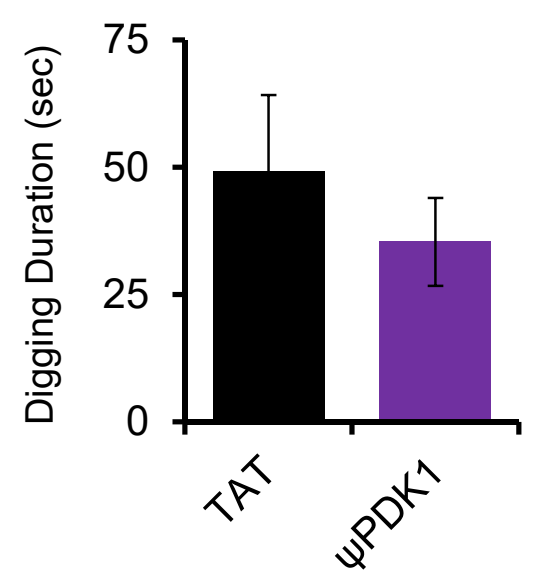

(C)

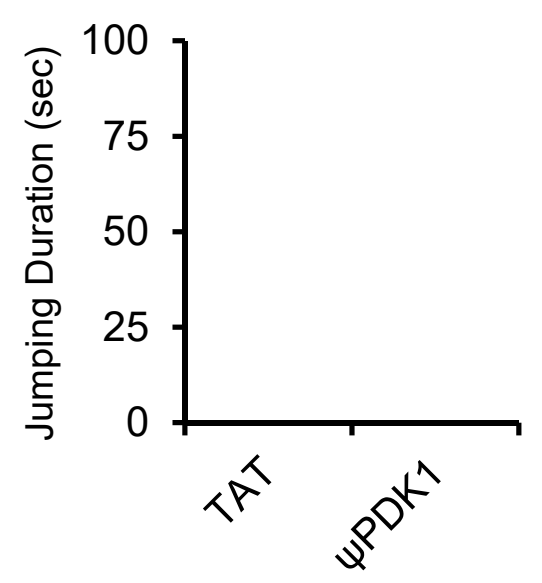

(E)

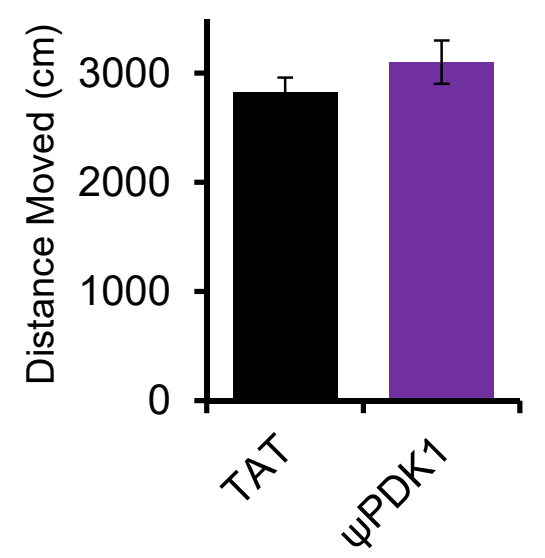

(B)

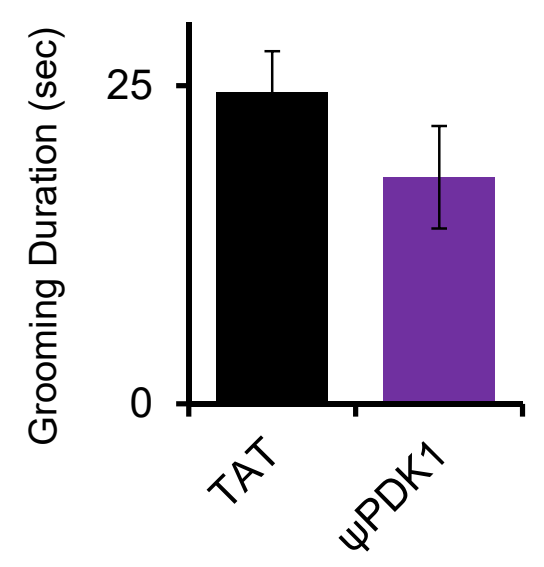

(D)

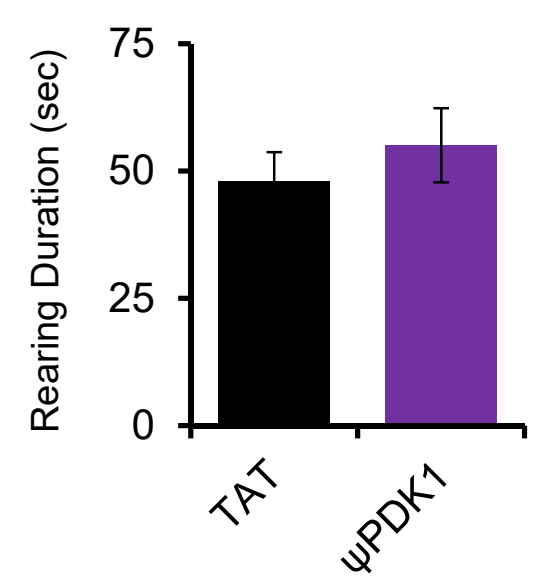

(F)

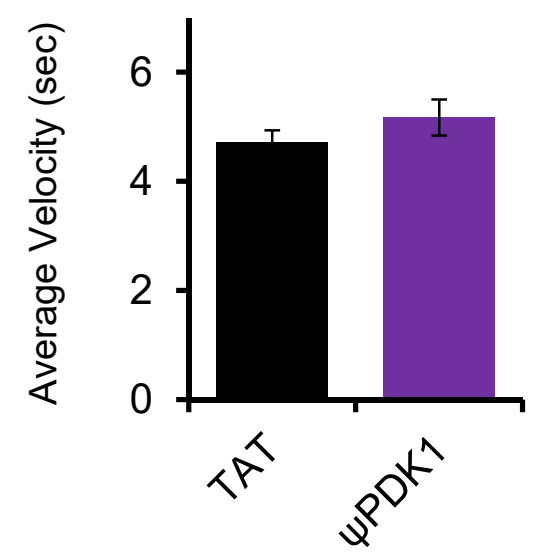


(G)

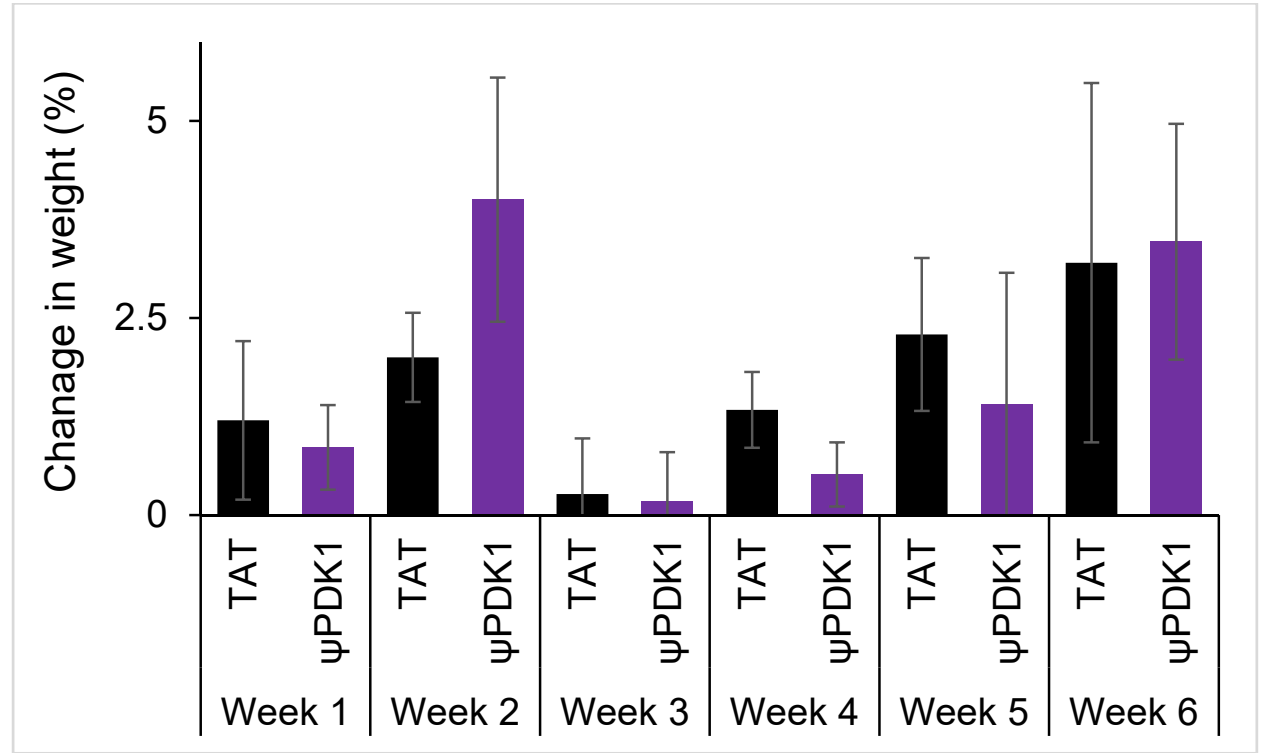

Supplementary Figure 4. Summary of behavioral experiments and toxicity of $\psi$ PDK1.

Digging duration (A), grooming duration (B), jumping duration (none of the mice jumped at all) $(\mathbf{C})$, rearing duration $(\mathbf{D})$, distance moved $(\mathbf{E})$, velocity $(\mathbf{F})$ and weight difference $(\mathbf{G})$ were measured and none difference was found between the $\psi \mathrm{PDK} 1$ or control group treatments. In addition there was no induction of seizures, strange behavioral or metabolic disorders in the $\psi \mathrm{PDK} 1$ or control group treatments. 
Supplementary Table 1. Heat-map of the ALSTE/D conservation in orthologs.

\begin{tabular}{|c|c|c|c|c|c|}
\hline Protein name & Human & Mouse & Rat & Chicken & Zebrafish \\
\hline Talin-1 (tln1) & ALSTD & ALSTD & ALSTD & ALSAD & FFYSD \\
\hline $\begin{array}{l}\text { Mitogen-activated protein kinase kinase kinase } 6 \\
\text { (MAP3K6) }\end{array}$ & ALSTD & TLPKD & TLPKD & $\begin{array}{l}\text { No protein } \\
\text { or no } \\
\text { homology }\end{array}$ & $\begin{array}{l}\text { No protein or } \\
\text { no homology }\end{array}$ \\
\hline $\begin{array}{l}\text { Arf-GAP with GTPase, ANK repeat and PH domain- } \\
\text { containing protein } 2 \text { (AGAP2) }\end{array}$ & ALSTD & ALSTD & ALSTD & $\begin{array}{l}\text { No protein } \\
\text { or no } \\
\text { homology }\end{array}$ & GFSVD \\
\hline $\begin{array}{l}\text { Constitutive coactivator of PPAR-gamma-like protein } 1 \\
\text { (FAM120A) }\end{array}$ & ALSTD & ALSTD & ALSTD & $\begin{array}{l}\text { No protein } \\
\text { or no } \\
\text { homology }\end{array}$ & $\begin{array}{l}\text { No protein or } \\
\text { no homology }\end{array}$ \\
\hline $\begin{array}{l}\text { Serine/threonine-protein phosphatase } 6 \text { regulatory } \\
\text { ankyrin repeat subunit C (ANKRD52) }\end{array}$ & ALSTD & ALSTD & ALSTD & ALSTD & ADHSQ \\
\hline Roundabout homolog 4 (ROBO4) & ALSTD & ILSAI & ILSAI & TKGSM & KGQSH \\
\hline Ephrin type-A receptor 4 (EPHA4) & ALSTD & ALSTD & ALSTD & ALSTD & ALATD \\
\hline $\begin{array}{l}\text { Probable tRNA (uracil-O(2)-)-methyltransferase } \\
\text { (METTL19) }\end{array}$ & ALSTD & VLPAA & VLPAA & $\begin{array}{l}\text { No protein } \\
\text { or no } \\
\text { homology }\end{array}$ & $\begin{array}{l}\text { No protein or } \\
\text { no homology }\end{array}$ \\
\hline Notchless protein homolog 1 (NLE1) & ALSTD & ALSTD & ALSTD & $\begin{array}{l}\text { No protein } \\
\text { or no } \\
\text { homology }\end{array}$ & ALSTD \\
\hline Sialidase-4 (NEU4) & ALSTD & ALSAD & ALSAD & AVFHG & AVSFD \\
\hline $\begin{array}{l}\text { SPARC-related modular calcium-binding protein } 2 \\
\text { (SMOC2) }\end{array}$ & ALSTD & ALSTD & ALSTD & ALSTD & $\begin{array}{l}\text { No protein or } \\
\text { no homology }\end{array}$ \\
\hline Sialidase-3 (NEU3) & ALSTD & AFSTD & AFSTD & $\begin{array}{l}\text { No protein } \\
\text { or no } \\
\text { homology }\end{array}$ & ALSES \\
\hline Pyruvate dehydrogenase kinase, mitochondrial (PDK) & ALSTD & ALSTD & ALSTD & ALSTE & ALSTD \\
\hline Transcription factor HES-1 (HES1) & ALSTD & ALSTD & ALSTD & ALSTD & $\begin{array}{l}\text { No protein or } \\
\text { no homology }\end{array}$ \\
\hline Protein NKG7 (NKG7) & ALSTD & ALTTD & ALSTD & $\begin{array}{l}\text { No protein } \\
\text { or no } \\
\text { homology }\end{array}$ & $\begin{array}{l}\text { No protein or } \\
\text { no homology }\end{array}$ \\
\hline Serine/threonine-protein kinase Nek8 (Nek8) & ALSTE & ALSTD & ALSAD & AVSNE & AVTNE \\
\hline Uncharacterized protein KIAA0947 (KIAA0947) & ALSTE & $\begin{array}{l}\text { No } \\
\text { protein or } \\
\text { no } \\
\text { homology }\end{array}$ & $\begin{array}{l}\text { No protein or } \\
\text { no homology }\end{array}$ & $\begin{array}{l}\text { No protein } \\
\text { or no } \\
\text { homology }\end{array}$ & $\begin{array}{l}\text { No protein or } \\
\text { no homology }\end{array}$ \\
\hline Myosin-15 (myo15) & ALSTE & LVDTF & $\begin{array}{l}\text { No protein or } \\
\text { no homology }\end{array}$ & $\begin{array}{l}\text { No protein } \\
\text { or no } \\
\text { homology }\end{array}$ & $\begin{array}{l}\text { No protein or } \\
\text { no homology }\end{array}$ \\
\hline NAC-alpha domain-containing protein 1 (Nacad) & ALSTE & PVPAE & $\begin{array}{l}\text { No protein or } \\
\text { no homology }\end{array}$ & $\begin{array}{l}\text { No protein } \\
\text { or no } \\
\text { homology }\end{array}$ & $\begin{array}{l}\text { No protein or } \\
\text { no homology }\end{array}$ \\
\hline $\begin{array}{l}\text { von Willebrand factor A domain-containing protein 5B2 } \\
\text { (VWA5B2) }\end{array}$ & ALSTE & AMSAE & AMSAE & $\begin{array}{l}\text { No protein } \\
\text { or no } \\
\text { homology }\end{array}$ & $\begin{array}{l}\text { No protein or } \\
\text { no homology }\end{array}$ \\
\hline ELKS/Rab6-interacting/CAST family member 1 (ERC1) & ALSTE & ALSSE & ALSTE & $\begin{array}{l}\text { No protein } \\
\text { or no } \\
\text { homology }\end{array}$ & MLSCE \\
\hline
\end{tabular}




\begin{tabular}{|c|c|c|c|c|c|}
\hline Protocadherin gamma-A1 (PCDHGA1) & ALSTE & PLSTQ & PLSTQ & $\begin{array}{l}\text { No protein } \\
\text { or no } \\
\text { homology }\end{array}$ & $\begin{array}{l}\text { No protein or } \\
\text { no homology }\end{array}$ \\
\hline Cytosolic phospholipase A2 zeta (Pla2g4f) & ALSTE & MLSPK & $\begin{array}{l}\text { No protein or } \\
\text { no homology }\end{array}$ & AFSQE & $\begin{array}{l}\text { No protein or } \\
\text { no homology }\end{array}$ \\
\hline Sortilin (SORT1) & ALSTE & ALSTE & ALSTE & $\begin{array}{l}\text { No protein } \\
\text { or no } \\
\text { homology }\end{array}$ & VYSIN \\
\hline Rho guanine nucleotide exchange factor 19 (Arhgef19) & ALSTE & ALCAL & ALCAQ & $\begin{array}{l}\text { No protein } \\
\text { or no } \\
\text { homology }\end{array}$ & PLLRR \\
\hline Protein kinase C delta KPCD (PRKCD) & ALSTE & ALSTE & ALTTD & ALTTE & ALSTE \\
\hline Centrosomal protein kizuna (PLK1S1) & ALSTE & SLFTE & $\begin{array}{l}\text { No protein or } \\
\text { no homology }\end{array}$ & AKSGQ & LSCSL \\
\hline WD repeat-containing protein 25 (WDR25) & ALSTE & ALNPE & DFRVT & $\begin{array}{l}\text { No protein } \\
\text { or no } \\
\text { homology }\end{array}$ & $\begin{array}{l}\text { No protein or } \\
\text { no homology }\end{array}$ \\
\hline Tetratricopeptide repeat protein 8 (TTC8) & ALSTE & SLSTE & SLSTE & $\begin{array}{l}\text { No protein } \\
\text { or no } \\
\text { homology }\end{array}$ & ALATE \\
\hline Tripartite motif-containing protein 15 (TRIM15) & ALSTE & ALRME & $\begin{array}{l}\text { No protein or } \\
\text { no homology }\end{array}$ & $\begin{array}{l}\text { No protein } \\
\text { or no } \\
\text { homology }\end{array}$ & $\begin{array}{l}\text { No protein or } \\
\text { no homology }\end{array}$ \\
\hline Tripartite motif-containing protein 64 (TRIM64) & ALSTE & $\begin{array}{l}\text { No } \\
\text { protein or } \\
\text { no } \\
\text { homology }\end{array}$ & $\begin{array}{l}\text { No protein or } \\
\text { no homology }\end{array}$ & $\begin{array}{l}\text { No protein } \\
\text { or no } \\
\text { homology }\end{array}$ & $\begin{array}{l}\text { No protein or } \\
\text { no homology }\end{array}$ \\
\hline $\begin{array}{l}\text { Putative tripartite motif-containing protein 64B } \\
\text { (TRIM64B) }\end{array}$ & ALSTE & $\begin{array}{l}\text { No } \\
\text { protein or } \\
\text { no } \\
\text { homology }\end{array}$ & $\begin{array}{l}\text { No protein or } \\
\text { no homology }\end{array}$ & $\begin{array}{l}\text { No protein } \\
\text { or no } \\
\text { homology }\end{array}$ & $\begin{array}{l}\text { No protein or } \\
\text { no homology }\end{array}$ \\
\hline $\begin{array}{l}\text { Putative tripartite motif-containing protein 64C } \\
\text { (TRIM64C) }\end{array}$ & ALSTE & $\begin{array}{l}\text { No } \\
\text { protein or } \\
\text { no } \\
\text { homology } \\
\end{array}$ & $\begin{array}{l}\text { No protein or } \\
\text { no homology }\end{array}$ & $\begin{array}{l}\text { No protein } \\
\text { or no } \\
\text { homology }\end{array}$ & $\begin{array}{l}\text { No protein or } \\
\text { no homology }\end{array}$ \\
\hline P-selectin glycoprotein ligand 1 (SELPLG) & ALSTE & VPSTE & APSTE & $\begin{array}{l}\text { No protein } \\
\text { or no } \\
\text { homology }\end{array}$ & $\begin{array}{l}\text { No protein or } \\
\text { no homology }\end{array}$ \\
\hline $\begin{array}{l}\text { UbiA prenyltransferase domain-containing protein } 1 \\
\text { (UBIAD1) }\end{array}$ & ALSTE & ALSTE & ALSTE & ALSTE & ALNTE \\
\hline Lys-63-specific deubiquitinase BRCC36 (BRCC3) & ALSTE & ALSTE & ALSTE & $\begin{array}{l}\text { No protein } \\
\text { or no } \\
\text { homology }\end{array}$ & ALSTE \\
\hline Olfactory receptor 10A4 (OR10A4) & ALSTE & $\begin{array}{l}\text { No } \\
\text { protein or } \\
\text { no } \\
\text { homology } \\
\end{array}$ & $\begin{array}{l}\text { No protein or } \\
\text { no homology }\end{array}$ & $\begin{array}{l}\text { No protein } \\
\text { or no } \\
\text { homology }\end{array}$ & $\begin{array}{l}\text { No protein or } \\
\text { no homology }\end{array}$ \\
\hline Maspardin (SPG21) & ALSTE & ALSTE & $\begin{array}{l}\text { No protein or } \\
\text { no homology }\end{array}$ & ALSTE & ALSQE \\
\hline Claudin-5 (Cldn5) & ALSTE & ALSAE & ALSAE & ALRPE & ALTTD \\
\hline
\end{tabular}


Supplementary Table 1. ALSTE or ALSTD sequences are found in 39 proteins in the human genome. The heat-map in Figure $2 \mathrm{G}$ is a depiction of the data provided in this Table, showing the conservation of ALSTE/D in orthologs of these proteins in mouse, rat, chicken and zebrafish; ALSTE/D is conserved only in PDK and $\delta \mathrm{PKC}$. The following amino acid substitutions were consider conserved for the analyses: $\mathrm{G} \leftrightarrow \mathrm{P} ; \mathrm{Y} \leftrightarrow \mathrm{F} ; \mathrm{I} \leftrightarrow \mathrm{L} \leftrightarrow \mathrm{V} ; \mathrm{M} \leftrightarrow \mathrm{C} ; \mathrm{S} \leftrightarrow \mathrm{T} ; \mathrm{N} \leftrightarrow \mathrm{Q} ; \mathrm{D} \leftrightarrow \mathrm{E}$ and $\mathrm{R} \leftrightarrow \mathrm{K}$. 


\section{Supplementary Table 2. MS and HPLC characterization of the peptides in this study}

\begin{tabular}{lllll}
\hline Peptide & \multicolumn{1}{c}{ Sequence } & MS. Cal. & MS Obs. & HPLC \\
\hline \multirow{2}{*}{ TAT } & YGRKKRRQRRR & 1558.8740 & 1558.2560 & $95 \%$ \\
$\psi$ PDDK & ALSTER & 716.7940 & 716.1278 & $98 \%$ \\
ALSAER & ALSAER & 686.7680 & 686.1983 & $97 \%$ \\
$\psi$ PDK1 & YGRKKRRQRRR-GSG-ALSTER & 2459.8190 & 2460.7845 & $95 \%$ \\
$\psi$ PDK2 & YGRKKRRQRRR-C-C-ALSTER & 2521.9670 & 2522.1892 & $92 \%$ \\
$\psi$ PDK3 & ALSTER-GSG-YGRKKRRQRRR & 2587.9940 & 2587.8901 & $93 \%$ \\
$\psi$ PDK4-Cyclic peptide & ALSTER-GSG-YGRKKRRQRRR & 2628.0150 & 2628.9018 & $94 \%$ \\
$\psi$ PDK5 & YGRKKRRQRRR-GSG-AASTER & 2417.7380 & 2417.9167 & $95 \%$ \\
$\psi$ PDK6 & YGRKKRRQRRR-GSG-ALATER & 2443.8200 & 2443.5114 & $94 \%$ \\
$\psi$ PDK7 & YGRKKRRQRRR-GSG-ALSAER & 2429.7930 & 2429.8940 & $93 \%$ \\
$\psi$ PDK 8 & YGRKKRRQRRR-GSG-ALSTAR & 2401.7830 & 2401.9358 & $95 \%$ \\
$\psi$ PDK9 & YGRKKRRQRRR-GSG-ALSTEA & 2374.7090 & 2375.0239 & $94 \%$
\end{tabular}

MS was done using MALDI technique and purity was determined by analytical HPLC. 


\section{REFERENCES}

(1) Kaiser, E.; Colescot, R. L.; Bossinge, C. D.; Cook, P. I. Anal. Biochem. 1970, 34, $595-598$. 